\title{
Obstruction after alcohol septal ablation is associated with cardiovascular mortality events
}

\author{
Josef Veselka, ${ }^{1}$ Pavol Tomašov, ${ }_{1}^{1}$ Jaroslav Januška, ${ }^{2}$ Jan Krejč̌i, ${ }^{3}$ Radka Adlová ${ }^{1}$
}

\begin{abstract}
'Department of Cardiology, 2nd Medical School, Charles University, University Hospital Motol, Prague, Czech Republic 2 Department of Cardiology, Cardiocentre Podlesí, Trìnec, Czech Republic

${ }^{3} 1$ st Department of Internal Medicine/Cardioangiology, International Clinical Research Centre, St Anne's University Hospital and Masaryk University, Brno, Czech Republic
\end{abstract}

\section{Correspondence to} Professor Josef Veselka, Department of Cardiology, Motol University Hospital, $V$ Uvalu 84, Prague 5, 15000, Czech Republic; aklesev007@gmail.com

Received 24 March 2016 Accepted 25 May 2016 Published Online First 1 September 2016

\section{SLinked}

- http://dx.doi.org/10.1136/ heartjnl-2016-309999

\section{CrossMark}

\author{
To cite: Veselka J, \\ Tomašov $P$, Januška J, et al. \\ Heart 2016;102:1793- \\ 1796.
}

\section{ABSTRACT}

Background Left ventricular outflow tract obstruction ( $\geq 30 \mathrm{~mm} \mathrm{Hg}$ at rest; LVOTO) is considered a possible risk of long-term outcomes in patients with hypertrophic cardiomyopathy (HCM). However, the influence of LVOTO on the occurrence of cardiovascular mortality events in patients after alcohol septal ablation (ASA) for obstructive HCM remains unresolved.

Methods We compared the outcomes of patients treated with ASA with residual LVOTO $<30 \mathrm{~mm} \mathrm{Hg}$ with those with residual LVOTO $\geq 30 \mathrm{~mm} \mathrm{Hg}$ at the first postdischarge check-up (1-6 months after the procedure). Results A total of 270 patients $(60 \pm 12$ years, median follow-up 5.1 years; $95 \% \mathrm{Cl} 4.5$ to 5.9 years) treated with a single ASA were included; $208(77 \%)$ and $62(23 \%)$ patients had post-ASA LVOTO $<30$ and $\geq 30 \mathrm{~mm} \mathrm{Hg}$ at the first postdischarge clinical check-up, respectively (LVOTO $13 \pm 6$ vs $50 \pm 27 \mathrm{~mm} \mathrm{Hg} ; p<0.01$ ). Freedom from cardiovascular mortality events at 1, 5 and 10 years were $99 \%(95 \% \mathrm{Cl} 96 \%$ to $100 \%)$ vs $94 \%$ (95\% Cl $85 \%$ to $98 \%), 95 \%(95 \% \mathrm{Cl} 89 \%$ to $97 \%)$ vs $80 \%(95 \% \mathrm{Cl}$ $66 \%$ to $89 \%$ ) and $82 \%$ (95\% Cl $69 \%$ to $89 \%$ ) vs $72 \%$ ( $95 \%$ Cl 55\% to $84 \%$ ) (log-rank test, $p<0.01$ ), respectively. In multivariable analysis adjusted for age at ASA, sex, baseline LVOTO and baseline septum thickness, the independent predictors of cardiovascular mortality events were early postdischarge LVOTO $\geq 30 \mathrm{~mm} \mathrm{Hg}$ (HR $2.95,95 \% \mathrm{Cl} 1.26$ to $6.91 ; \mathrm{p}=0.01)$ and baseline septum thickness (HR 1.07, 95\% Cl 1.01 to 1.13; $p=0.02$ ).

Conclusions After ASA for obstructive HCM, LVOTO $\geq 30 \mathrm{~mm} \mathrm{Hg}$ at the first postdischarge clinical check-up is associated with significantly higher occurrence of subsequent cardiovascular mortality events.

\section{INTRODUCTION}

Hypertrophic cardiomyopathy (HCM) is an inherited myocardial disease characterised by cardiac hypertrophy in the absence of hypertension and aortic valve disease. ${ }^{1}{ }^{2}$ Left ventricular outflow tract obstruction (LVOTO) is present in approximately two-thirds of patients. In recent studies, alcohol septal ablation (ASA) was associated with excellent long-term survival, ${ }^{3-9}$ even comparable with that of an age-matched and sex-matched general population. ${ }^{78}$ However, some patients who have undergone ASA present residual LVOTO. Several studies have suggested that LVOTO in patients with HCM is a strong and independent predictor of progression to severe symptoms of heart failure or death. ${ }^{10}{ }^{11}$ However, the relationship between post-ASA residual obstruction and the occurrence of subsequent adverse cardiovascular events remains unresolved.
Therefore, we report here a multicentre comparison of the long-term occurrence of cardiovascular mortality events in patients treated with ASA and early postprocedural LVOTO of $<30 \mathrm{~mm} \mathrm{Hg}$ vs $\geq 30 \mathrm{~mm} \mathrm{Hg}$.

\section{METHODS}

The study design is based on a multicentre ASA registry in which patients were prospectively collected and retrospectively reviewed. A total of 270 patients $(60 \pm 12$ years, women $53 \%)$ were enrolled with highly symptomatic obstructive HCM treated with ASA at three centres during the period from 1998 to 2015. All patients had to undergo a single ASA and submit to long-term follow-up at the centre where ASA was performed. Patients who experienced the cardiovascular mortality event during the first postprocedural month were not enrolled. Written informed consent was obtained from each patient, and the local ethics committees approved the study.

The diagnosis of obstructive HCM was established by experienced cardiologists based on echocardiographic and/or cardiac magnetic resonance examinations, with wall thickness $\geq 15 \mathrm{~mm}$, maximal (provocable) LVOTO $\geq 50 \mathrm{~mm} \mathrm{Hg}$ and severe symptoms (New York Heart Association (NYHA) class III/IV and/or exercise syncopes). ASA was indicated after a detailed multidisciplinary evaluation based on local clinical experience and the patient's preference.

All interventional procedures were performed by interventional cardiologists at centres with special cardiomyopathy clinics. The technical details of the interventions were described previously. All centres used echocardiography-guided ASA and low doses of injected alcohol. ${ }^{12-14}$

All patients underwent routine clinical and echocardiographic check-ups 1-6 months after ASA and then every year, depending on the local customs of the HCM centre. Patients were assigned to one of two groups according to residual LVOTO at the first postdischarge clinical check-up after ASA (LVOTO $<30 \mathrm{~mm} \mathrm{Hg}$ and LVOTO $\geq 30 \mathrm{~mm} \mathrm{Hg}$ ).

\section{Definitions}

The primary endpoint was the occurrence of cardiovascular mortality events (cardiovascular death, the first appropriate implantable cardioverter-defibrillator (ICD) discharge and resuscitation) in patients treated with ASA and early postprocedural LVOTO of $<30 \mathrm{~mm} \mathrm{Hg}$ vs $\geq 30 \mathrm{~mm} \mathrm{Hg}$. Cardiovascular death was defined as death related to any cardiovascular disease, including stroke. In 
patients with an implanted ICD, device interventions triggered by ventricular fibrillation or ventricular tachycardia were considered as appropriate discharges.

\section{Statistical analysis}

All data were evaluated by two independent statisticians. Data were presented as means \pm SDs for continuous variables and proportions for categorical variables. Student's t test was used to assess the statistical significance of continuous variables. Cox proportional hazards regression was used to identify predictors of cardiovascular mortality events. Generalised Therneau and Grambsch test based on scaled Schoenfeld residuals was used to check the proportional hazard assumption in Cox's model. Neither the tests for individual covariates in univariate models nor the global test in multiple model showed any statistically significant violation of the assumption. Graphical assessment based on log-log plots gave the parallel curves. The following clinical and echocardiographic variables with potential impact on cardiovascular mortality events were evaluated, first in a univariate model: age at ASA, sex, LVOTO, septum thickness and left atrial diameter, both at baseline and at the last clinical check-up. Variables with values of $\mathrm{p}<0.15$ were then entered into a multivariable analysis, which was performed using backward stepwise Cox regression. The long-term occurrence of cardiovascular mortality events was estimated using the Kaplan-Meier method, and differences between groups were assessed by the log-rank test. Kaplan-Meier curves of groups with LVOTO $<30 \mathrm{~mm} \mathrm{Hg}$ and LVOTO $\geq 30 \mathrm{~mm} \mathrm{Hg}$ were adjusted for age at ASA (60 years), baseline septum thickness $(20 \mathrm{~mm})$, baseline LVOTO (70 $\mathrm{mm} \mathrm{Hg})$ and sex (50\% women). A value of $\mathrm{p}<0.05$ was considered statistically significant. The statistical software, GraphPad, release V.6.05 (GraphPad Software, La Jolla, California, USA) was used for statistical analysis.

\section{RESULTS}

A total of 310 patients with ASA were treated; 35 (11.3\%) patients were excluded due to repeat septal reduction therapy; four $(1.3 \%)$ patients died before the first post-ASA check-up; one patient moved abroad.

A total of 270 patients $(86 \%, 60 \pm 12$ years) treated with a single ASA were included; 208 (77\%) and 62 (23\%) patients had post-ASA LVOTO $<30 \mathrm{~mm} \mathrm{Hg}$ and $\geq 30 \mathrm{~mm} \mathrm{Hg}$ at the time of the first postdischarge clinical check-up $(2.3 \pm 1.5$ months after ASA), respectively (LVOTO $13 \pm 6$ vs $50 \pm 27 \mathrm{~mm} \mathrm{Hg}$; $<<0.01$ ). Both groups had similar baseline characteristics (table 1). No patient was lost to follow-up. The clinical and echocardiographic data at the time of the last clinical check-up are summarised in table 1. A total of 44 deaths (16\%) occurred after the ASA procedure and before the last clinical check-up (1582 patient-years), yielding an all-cause mortality rate of $2.78 \%$ per year.

The incidence of cardiovascular mortality events is summarised in table 2.

Kaplan-Meier survival curves are shown in figures 1 and 2. Freedom from cardiovascular mortality events in LVOTO $<30 \mathrm{~mm} \mathrm{Hg}$ group versus LVOTO $\geq 30 \mathrm{~mm} \mathrm{Hg}$ group at 1,5 and 10 years were $99 \%$ (95\% CI $96 \%$ to $100 \%)$ vs $94 \%(95 \%$ CI $85 \%$ to $98 \%)$, $95 \%$ (95\% CI $89 \%$ to $97 \%)$ vs $80 \%(95 \%$ CI $66 \%$ to $89 \%$ ) and $82 \%(95 \%$ CI $69 \%$ to $89 \%)$ vs $72 \%(95 \%$ CI $55 \%$ to $84 \%$ ) (log-rank test, p<0.01), respectively. Unadjusted and adjusted freedom from cardiovascular mortality events are significantly different for both groups after stratification by early postdischarge LVOTO (log-rank, $p=0.002$; $\mathrm{p}=0.019$ after adjustment).
Table 1 Clinical and echocardiographic characteristics at baseline, at early postdischarge clinical check-up and at the last check-up

\begin{tabular}{|c|c|c|c|}
\hline & $\begin{array}{l}\text { LVOTO } \\
<30 \mathrm{~mm} \mathrm{Hg} \\
\mathrm{N}=208\end{array}$ & $\begin{array}{l}\text { LVOTO } \\
\geq 30 \mathrm{~mm} \mathrm{Hg} \\
\mathrm{N}=62\end{array}$ & $\mathrm{p}$ Value \\
\hline Age, years & $58.9 \pm 11.9$ & $57.9 \pm 14.1$ & 0.559 \\
\hline Sex, females, \% & $109(52.4)$ & $34(54.8)$ & 0.773 \\
\hline Alcohol, mL & $1.7 \pm 0.8$ & $1.8 \pm 0.6$ & 0.123 \\
\hline CKMB max, $\mu$ kat/L & $3.0 \pm 2.1$ & $2.8 \pm 1.4$ & 0.806 \\
\hline \multicolumn{4}{|l|}{ Dyspnoea, NYHA class } \\
\hline Baseline & $2.9 \pm 0.5$ & $3.0 \pm 0.5$ & 0.498 \\
\hline Early post-ASA check-up & $1.6 \pm 0.7$ & $1.9 \pm 0.7$ & 0.003 \\
\hline Last clinical check-up & $1.7 \pm 0.7$ & $2.0 \pm 0.7$ & 0.003 \\
\hline \multicolumn{4}{|l|}{ Angina, CCS class } \\
\hline Baseline & $1.5 \pm 1.2$ & $1.4 \pm 1.3$ & 0.356 \\
\hline Early post-ASA check-up & $0.3 \pm 0.6$ & $0.4 \pm 0.8$ & 0.779 \\
\hline Last clinical check-up & $0.2 \pm 0.5$ & $0.3 \pm 0.6$ & 0.727 \\
\hline \multicolumn{4}{|c|}{ Left ventricular outflow gradient, $\mathrm{mm} \mathrm{Hg}$} \\
\hline Baseline & $64.1 \pm 39.5$ & $92.8 \pm 39.8$ & $<0.001$ \\
\hline Early post-ASA check-up & $12.8 \pm 6.0$ & $49.9 \pm 26.5$ & $<0.001$ \\
\hline Last clinical check-up & $13.3 \pm 11.4$ & $33.2 \pm 29.7$ & $<0.001$ \\
\hline \multicolumn{4}{|l|}{ Left ventricular diameter, mm } \\
\hline Baseline & $42.4 \pm 5.3$ & $42.8 \pm 6.1$ & 0.690 \\
\hline Early post-ASA check-up & $45.4 \pm 5.1$ & $45.7 \pm 5.8$ & 0.684 \\
\hline Last clinical check-up & $46.5 \pm 5.2$ & $46.7 \pm 5.9$ & 0.764 \\
\hline \multicolumn{4}{|l|}{ Left ventricular ejection fraction, \% } \\
\hline Baseline & $73.2 \pm 9.9$ & $71.3 \pm 9.9$ & 0.169 \\
\hline Early post-ASA check-up & $70.3 \pm 10.1$ & $69.6 \pm 9.4$ & 0.409 \\
\hline Last clinical check-up & $68.5 \pm 8.7$ & $67.3 \pm 10.2$ & 0.303 \\
\hline \multicolumn{4}{|l|}{ Basal septum thickness, mm } \\
\hline Baseline & $20.5 \pm 4.1$ & $22.4 \pm 5.9$ & 0.009 \\
\hline Early post-ASA check-up & $15.8 \pm 4.9$ & $18.7 \pm 5.2$ & $<0.001$ \\
\hline Last clinical check-up & $13.5 \pm 3.6$ & $16.2 \pm 4.6$ & $<0.001$ \\
\hline \multicolumn{4}{|l|}{ Left atrium diameter, $\mathrm{mm}$} \\
\hline Baseline & $46.2 \pm 6.0$ & $48.1 \pm 7.4$ & 0.043 \\
\hline Early post-ASA check-up & $45.2 \pm 5.9$ & $47.0 \pm 7.2$ & 0.052 \\
\hline Last clinical check-up & $46.4 \pm 6.7$ & $48.2 \pm 7.4$ & 0.075 \\
\hline Mean follow-up duration, years & $5.8 \pm 4.1$ & $5.2 \pm 4.0$ & \\
\hline
\end{tabular}

ASA, alcohol septal ablation; CCS, Canadian Cardiovascular Society; LVOTO, left ventricular outflow tract obstruction.

Table 2 Cardiovascular mortality events during follow-up

\begin{tabular}{lcll}
\hline & $\begin{array}{l}\text { LVOTO } \\
<30 \mathrm{~mm} \mathrm{Hg} \\
\mathrm{N}=208\end{array}$ & $\begin{array}{l}\text { LVOTO } \\
\mathbf{N}=62\end{array}$ & $\mathbf{~ m m ~ H g}$ \\
\hline Cardiovascular death & $12(5.8 \%)$ & $6(9.7 \%)$ & 0.353 \\
The first appropriate ICD discharge & $2(1.0 \%)$ & $4(6.5 \%)$ & 0.007 \\
Resuscitation & $1(0.5 \%)$ & $3(4.8 \%)$ & 0.011 \\
\hline LVOTO, left ventricular outflow tract obstruction. & &
\end{tabular}

In multivariable analysis adjusted for age at ASA, sex, baseline LVOTO and baseline septum thickness, the independent predictors of cardiovascular mortality events were early postdischarge LVOTO $\geq 30 \mathrm{~mm} \mathrm{Hg}$ (HR 2.95, 95\% CI 1.26 to $6.91 ; \mathrm{p}=0.01$ ) and baseline septum thickness (HR 1.07, 95\% CI 1.01 to 1.13 ; $\mathrm{p}=0.02)$.

\section{DISCUSSION}

In this study, the following principal findings are reported: (i) patients with obstructive HCM treated with a single ASA and 


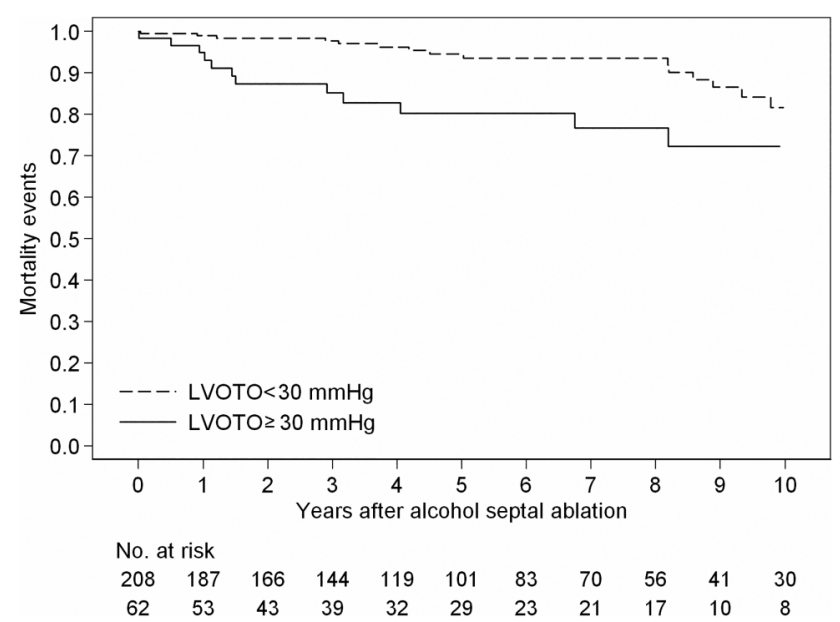

Figure 1 Kaplan-Meier curves describing freedom from cardiovascular mortality events in patients with residual left ventricular outflow tract obstruction (LVOTO) $<30 \mathrm{~mm} \mathrm{Hg}$ and $\geq 30 \mathrm{~mm} \mathrm{Hg}$.

subsequent residual LVOTO $\geq 30 \mathrm{~mm} \mathrm{Hg}$ detected early after ASA have a higher rate of post-ASA cardiovascular mortality events than those with no or mild residual LVOTO $(<30 \mathrm{~mm} \mathrm{Hg})$; (ii) the independent predictors of cardiovascular mortality events in these patients are early postdischarge LVOTO $\geq 30 \mathrm{~mm} \mathrm{Hg}$ (HR 2.95) and baseline septum thickness (HR 1.07).

From the pathophysiological point of view, a variety of mechanisms are responsible for the negative clinical consequences of LVOTO. Myocardial ischaemia could be caused by increased LV work, increased oxygen consumption and simultaneous microvascular coronary artery disease. Also, a significant LVOTO results in increased LV wall stress. On the other hand, it has been demonstrated that the elimination of obstruction can lead to an acute decrease in oxygen myocardial consumption ${ }^{15}$ and a continuous decrease in LV myocardial mass, ${ }^{16}$ which might be essential mechanisms for the long-term improvement of a patient's prognosis.

Maron et $a l^{10}$ described a deleterious effect of LVOTO defined as $\geq 30 \mathrm{~mm} \mathrm{Hg}$ on the long-term outcomes of patients with HCM. Sorajja $e t a^{17}$ found a strong correlation between

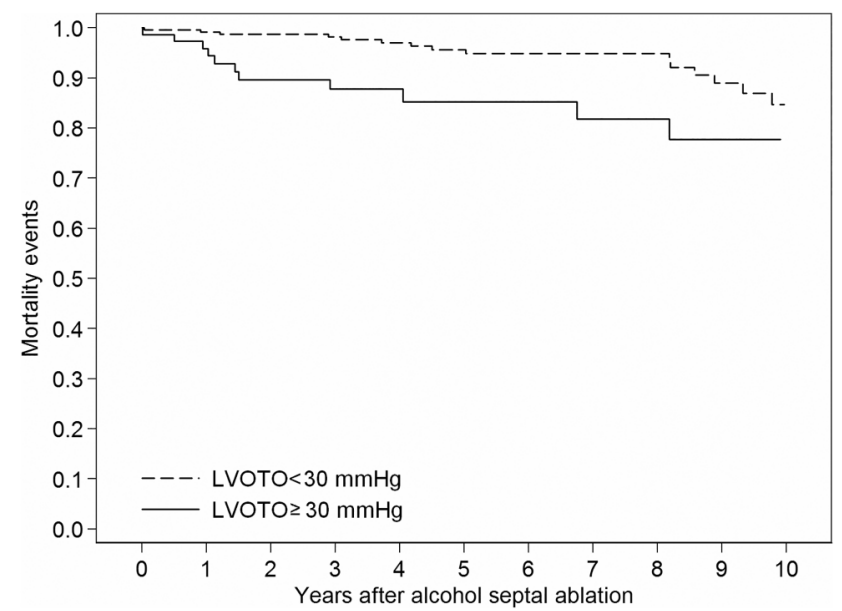

Figure 2 Kaplan-Meier curves describing freedom from cardiovascular mortality in patients with residual left ventricular outflow tract obstruction (LVOTO) $<30 \mathrm{~mm} \mathrm{Hg}$ and $\geq 30 \mathrm{~mm} \mathrm{Hg}$ (adjustment for age, sex, baseline LVOTO and baseline septum thickness). the severity of LVOTO and outcome among patients with mildly symptomatic or asymptomatic obstructive HCM. Elliott et al demonstrated that LVOTO $\geq 30 \mathrm{~mm} \mathrm{Hg}$ was an independent predictor of sudden cardiac death among an unselected population of obstructive patients with HCM. They also found that the relative risk of sudden cardiac death or ICD discharge increased by $1 \%$ for each $1 \mathrm{~mm} \mathrm{Hg}$ of LVOTO. ${ }^{18}$ Similarly, data from the Euro-ASA registry showed that each $\mathrm{mm} \mathrm{Hg}$ increase in post-ASA LVOTO was associated with a $1 \%$ increase in the long-term risk of all-cause death. ${ }^{6}$ In this study, early post-ASA LVOTO $\geq 30 \mathrm{~mm} \mathrm{Hg}$ was associated with a threefold increase in the risk of cardiovascular mortality events during long-term follow-up. Thus, there is a growing body of evidence consistently suggesting that LVOTO in patients with HCM has negative clinical implications and that its elimination/reduction can be associated with reduced symptoms and improved prognoses. Similarly, the pre-ASA thickness of the basal septum is an independent risk factor affecting the occurrence of sudden cardiac death $^{12} 1119$ and cardiovascular mortality events.

Notably, the present study has several limitations. First, some inherent limitations are associated with the retrospective and observational design of this study. Second, as was demonstrated in the past, some patients present with thicker basal septa and slower haemodynamic improvement after ASA. The ASA-related reduction of LVOTO may be determined by individual factors and can last 1-6 months. ${ }^{20}$ Therefore, each participating centre had its own schedule for post-ASA clinical examinations. Thus, we cannot clearly recommend when patients should be examined post ASA to assess the long-term postprocedural prognosis. However, this limitation does not dispute the fact that the longterm effects of LVOTO are deleterious and negatively impact the occurrence of cardiovascular mortality events.

\section{CONCLUSIONS}

After ASA for obstructive HCM, residual obstruction $\geq 30 \mathrm{~mm} \mathrm{Hg}$ at the early postdischarge clinical check-up is associated with a significantly higher occurrence of post-ASA cardiovascular mortality events.

\section{Key messages}

What is already known on this subject?

Left ventricular outflow tract obstruction is associated with increased mortality in patients with hypertrophic cardiomyopathy. There is a growing body of non-randomised evidence suggesting that reduction/elimination of the outflow gradient might be associated with better clinical outcomes.

\section{What might this study add?}

This study is the first to demonstrate that patients who have undergone alcohol septal ablation and then achieve outflow gradient $<30 \mathrm{~mm} \mathrm{Hg}$ soon after the procedure present a significantly lower occurrence of cardiovascular mortality events during long-term follow-up.

\section{How might this impact on clinical practice?}

The results of this study suggest that alcohol septal ablation with complete elimination of obstruction might be advantageous for symptomatic patients with hypertrophic obstructive cardiomyopathy. Additional studies supporting this data are needed. 
Acknowledgements The authors are grateful to statisticians Eva Hansvenclova and Dr Marek Maly for their assistance with statistical analysis. The authors also thank their colleagues responsible for the HCM clinics at all participating centres.

Contributors JV drafted the MS, performed statistical analysis, conceived and designed the research and acquired the data; JK, JJ, RA and PT made critical revision of the MS and acquired the data.

Funding Supported by MH CZ-DRO, University Hospital Motol, Prague, Czech Republic 00064203 and Grant MH CZ 15-34904A.

Competing interests None declared.

Ethics approval Motol Multicentre Ethics Committee.

Provenance and peer review Not commissioned; externally peer reviewed.

\section{REFERENCES}

1 Elliott PM, Anastasakis A, Borger MA, et al. 2014 ESC Guidelines on diagnosis and management of hypertrophic cardiomyopathy: the Task Force for the Diagnosis and Management of Hypertrophic Cardiomyopathy of the European Society of Cardiology (ESC). Eur Heart J 2014;35:2733-79.

2 Gersh BJ, Maron BJ, Bonow RO, et al. 2011 ACCF/AHA guideline for the diagnosis and treatment of hypertrophic cardiomyopathy: a report of the American College of Cardiology Foundation/American Heart Association Task Force on Practice Guidelines. Circulation 2011;124:e783-831.

3 Seggewiss $H$, Rigopoulos A, Welge $D$, et al. Long-term follow-up after percutaneous septal ablation in hypertrophic obstructive cardiomyopathy. Clin Res Cardiol 2007:96:856-63.

4 Lyne JC, Kilpatrick T, Duncan A, et al. Long-term follow-up of the first patients to undergo transcatheter alcohol septal ablation. Cardiology 2010;116:168-73.

5 Vriesendorp PA, Liebregts M, Steggerda RC, et al. Long-term outcomes after medical and invasive treatment in patients with hypertrophic cardiomyopathy. JACC Heart Fail 2014;2:630-6.

6 Veselka J, Jensen MK, Liebregts M, et al. Long-term clinical outcome after alcohol septal ablation for obstructive hypertrophic cardiomyopathy: results from the Euro-ASA registry. Eur Heart J 2016;37:1517-23.

7 Veselka J, Krejči J, Tomašov P, et al. Long-term survival after alcohol septal ablation for hypertrophic obstructive cardiomyopathy: a comparison with general population. Eur Heart J 2014;35:2040-5.
8 Jensen MK, Prinz C, Horstkotte D, et al. Alcohol septal ablation in patients with hypertrophic obstructive cardiomyopathy: low incidence of sudden cardiac death and reduced risk profile. Heart 2013;99:1012-17.

9 Kuhn H, Lawrenz T, Lieder F, et al. Survival after transcoronary ablation of septal hypertrophy in hypertrophic obstructive cardiomyopathy (TASH): a 10 year experience. Clin Res Cardiol 2008;97:234-43.

10 Maron M, Olivotto I, Betocchi S, et al. Effect of left ventricular outflow tract obstruction on clinical outcome in hypertrophic cardiomyopathy. New Engl J Med 2003;348:295-303.

11 O'Mahony $\mathrm{C}$, Jichi F, Pavlou M, et al. A novel clinical risk prediction model for sudden cardiac death in hypertrophic cardiomyopathy (HCM Risk-SCD). Eur Heart J 2014;35:2010-20.

12 Veselka J, Duchoňová R, Procházková Š, et al. Effects of varying ethanol dosing in percutaneous septal ablation for obstructive hypertrophic cardiomyopathy on early hemodynamic changes. Am J Cardiol 2005;95:675-8.

13 Veselka J, Tomašov P, Zemánek D. Long-term effects of varying alcohol dosing in percutaneous septal ablation for obstructive hypertrophic cardiomyopathy: a randomized study with a follow-up up to 11 years. Can J Cardiol 2011;27:763-7.

14 Veselka J, Lawrenz T, Stellbrink C, et al. Early outcomes of alcohol septal ablation for hypertrophic obstructive cardiomyopathy: a European multicenter and multinational study. Catheter Cardiovasc Interv 2014;84:101-7.

15 Cannon RO, McIntosh CL, Schenke WH, et al. Effect of surgical reduction of left ventricular outflow obstruction on hemodynamics, coronary flow, and myocardial metabolism in hypertrophic cardiomyopathy. Circulation 1989;79:766-75.

16 Mazur W, Nagueh SF, Lakkis NM, et al. Regression of left ventricular hypertrophy after nonsurgical septal reduction therapy for hypertrophic obstructive cardiomyopathy. Circulation 2001;103:1492-6.

17 Sorajja P, Nishimura RA, Gersh BJ, et al. Outcome of mildly symptomatic or asymptomatic obstructive hypertrophic cardiomyopathy: a long-term follow-up study. J Am Coll Cardiol 2009;54:234-41.

18 Elliott PM, Gimeno JR, Tom é MT, et al. Left ventricular outflow tract obstruction and sudden death risk in patients with hypertrophic cardiomyopathy. Eur Heart J 2006;27:1933-41.

19 Spirito $\mathrm{P}$, Bellone $\mathrm{P}$, Harris KM, et al. Magnitude of left ventricular hypertrophy and risk of sudden death in hypertrophic cardiomyopathy. $N$ Engl J Med 2000;342:1778-85.

20 Veselka J, Duchoňová R, Páleníčková J, et al. Age-related hemodynamic and morphologic differences in patients undergoing alcohol septal ablation for hypertrophic obstructive cardiomyopathy. Circ J 2006;70:880-4. 